\title{
Outcome of knee injuries in general practice: 1-year follow-up
}

\author{
Harry PA Wagemakers, Pim AJ Luijsterburg, Edith $M$ Heintjes, \\ Marjolein Y Berger, Jan Verhaar, Bart W Koes and Sita MA Bierma-Zeinstra
}

\section{ABSTRACT}

\section{Background}

Knee injuries may lead to pain and to functional limitations in the activities of daily living. Patients with knee injuries are frequently seen in general practice; however, the outcome and management in these patients is not known.

Aim

To assess the outcome and management of knee injuries at 12 months' follow-up in general practice.

Design of study

A prospective observational cohort study with a 1-year follow-up.

Setting

Primary health care.

\section{Method}

Adult patients consulting their GP after knee injury $(n=134)$ participated in the cohort. A magnetic resonance imaging scan was carried out and patients were diagnosed as either no lesion or an isolated meniscal tear, an isolated collateral or cruciate ligament lesion, or a combination. Follow-up questionnaires were filled in up to 12 months' follow-up.

\section{Results}

At 12 months' follow-up, 34 patients reported full recovery and 67 patients reported major improvement. At baseline, 37 patients (28\%) were referred to physical therapy and 17 patients (13\%) were referred to secondary care. During 1 year of follow-up, another 21 referrals to physical therapy and 11 referrals to secondary care took place. The pain severity decreased the most, and the Lysholm knee score increased in the majority of patients during the first 3 months after injury. In total, 18 arthroscopies were performed in 15 patients. One patient underwent an anterior cruciate ligament reconstruction.

\section{Conclusion}

The vast majority of patients report clinically relevant recovery. There is no clear difference in outcomes between patients with meniscal tears or ligament lesions and patients without these diagnoses.

\section{Keywords}

family practice; knee injuries; outcome studies.

\section{INTRODUCTION}

Patients with knee injuries often consult a GP. The annual incidence of consultations is estimated at 5.3 per 1000 patients. ${ }^{1}$ Knee injuries may lead to complaints and to functional limitations at work, in sports activities, or activities of daily living, and bother the patient in both the short term ${ }^{2}$ and long term. ${ }^{3,4}$

Knowledge on the outcome of knee injuries is based on reports from secondary care cohorts usually representing the more serious injuries., Some studies have reported on the outcome of knee injuries diagnosed with magnetic resonance imaging (MRI) and were summarised in a review by Boks et al. ${ }^{7}$ Although the study populations were small, these studies indicated that at follow-up the majority of patients had no persistent complaints. ${ }^{7}$

The outcome of knee injuries in primary care is, to the authors' knowledge, not yet known. In Dutch primary care a wait-and-see policy is at present the advocated initial management. ${ }^{8}$

The objective of the present study is to determine the outcome and management of patients consulting the GP with knee injuries during 1 year of follow-up.

HPA Wagemakers, PT, Msc, researcher; PAJ Luijsterburg, PhD, associate professor; MY Berger; MD, PhD; J Verhaar, $M D, P h D$, professor of orthopaedics; $B W$ Koes; $P h D$, professor of general practice; SMA Bierma-Zeinstra, PhD, associate professor, Erasmus Medical Centre, Department of General Practice, Rotterdam, The Netherlands. EM Heintjes, PhD, research associate, Pharmo Institute, Utrecht, the Netherlands.

Address for correspondence

Harry PA Wagemakers, Department of General Practice, Erasmus Medical Center Rotterdam, PO Box 2040, 3000 CA Rotterdam, The Netherlands.

E-mail: hpa.wagemakers@dordrecht.nl

Submitted: 20 April 2009; Editor's response: 26 May 2009; final acceptance: 27 May 2009.

(C) British Journal of General Practice

This is the full-length article of an abridged version published in print. Cite this article as: Br J Gen Pract 2010; DOI: 10.3399/bjgp10X483157. 


\section{METHOD}

\section{Design}

The present study was part of a large prospective observational cohort study on knee complaints in general practice. ${ }^{9}$ Forty GPs from five municipalities in the southwest region of The Netherlands, participating in the Erasmus MC GP research network HONEUR, asked patients with all new knee complaints to participate in the general cohort study with a follow-up of 12 months. This network represents a total patient population of around 84000 patients. Detailed information about the study design has been published elsewhere. ${ }^{9}$

Patients were included in the present study if the complaint was brought on by trauma within 5 weeks of presentation, and they were aged 18-65 years. These patients were asked to undergo MRI. Patients with MRI contraindications (pregnancy, metal implants, or a pacemaker) were excluded. Detailed information about the MRI protocol is also published elsewhere. ${ }^{10}$

\section{Data collection}

At baseline the patients filled in a questionnaire to collect data on age, sex, socioeconomic status, history of previous knee injuries and/or operations, general health, present symptoms, the mechanism of injury, the level of activity in both work and sports, and the management initiated by the GP at baseline. ${ }^{9}$ The severity of pain was assessed with a validated 11-point numeric rating scale (NRS) ranging from 0 (no pain) to 10 (unbearable pain). ${ }^{11}$ The Lysholm knee score provides information on instability and functional limitations such as walking and stair climbing. ${ }^{12}$ The Lysholm score ranged from 0 (worse) to 100 (best) and was obtained using a standard form, filled in by the patient. The Tegner knee function score (range 0-10) was used to determine the level of activity in work and sports prior to the knee injury. ${ }^{12}$

MRI was selected as the reference diagnostic test because it is highly accurate in detecting meniscal tears and ligament lesions. ${ }^{13,14} \mathrm{MRI}$ was scheduled 2-6 weeks after the initial trauma, using a 1.0 Tesla General Electric device. Two radiologists determined the results of the MRI independently, based on a standardised classification form. The results of the MRI were also used to evaluate the diagnostic value of history taking and physical examination. ${ }^{15-17}$

After the MRI, a standardised physical examination was carried out by a trained physical therapist. Physical examination consisted of inspection, palpation, assessment of effusion, passive range of motion, meniscal tests, and ligament stability tests, and was performed in both the injured and the contralateral knee. ${ }^{9}$

\section{How this fits in}

Patients with complaints due to knee injuries are frequently seen in general practice however, outcome of these complaints is not well documented. From

this study it emerges that the vast majority of these patients report clinically relevant recovery regardless of whether there is a meniscal tear, ligament lesion involved, or no damage at all. Therefore a wait-and-see policy as advocated by the Dutch guideline for traumatic knee disorders is recommended.

To avoid influencing the patient's behaviour or the GP's management, neither the patients nor their GPs were informed about the results of the MRI or physical examination during the 12 months' follow-up.

At 3, 6, and 12 months after the knee injury, a follow-up questionnaire was sent to the participating patients, who were asked to return the questionnaire by post. If patients did not return the questionnaire a reminder was sent by post, or a telephone call was made to the patient. These questionnaires collected data on medical consumption (GP consultations, referral to secondary care or to physical therapy). Also the severity of pain (NRS11) and the Lysholm ${ }^{12}$ scores were obtained. At 12 months' follow-up, the patients also reported on their perceived recovery using a 7-item Likert scale categorised as full recovery, major improvement, minor improvement, approximately equal, minor deterioration, major deterioration, and worse than ever. The categories full recovery and major improvement were defined as clinically relevant recovery.

\section{Statistical analysis}

The results are presented with descriptive statistics (frequencies, median, means, and standard deviation [SD]) using SPSS (version 11.0). The pain score and Lysholm score are presented for the total group and the subgroups with and without any lesion, as well as for four specific subgroups: isolated meniscal tear, isolated cruciate or collateral ligament lesion, or a combination. Perceived recovery is reported for the total group, as well as for the subgroups with and without any lesion.

\section{RESULTS}

\section{Study population}

One hundred and thirty-four of 184 eligible patients (73\%) consulting their GP with a knee injury were included. The remaining 50 patients filled in the baseline and follow-up questionnaires because they participated in the general cohort study, but were unwilling or unable to participate in this additional study. The reasons for non-participation are listed in Figure 1. The groups 'participants' and 'nonparticipants' showed no significant differences at baseline (Table 1) with regard to sex (odds ratio [OR] 
Figure 1. Flow chart of eligible patients.

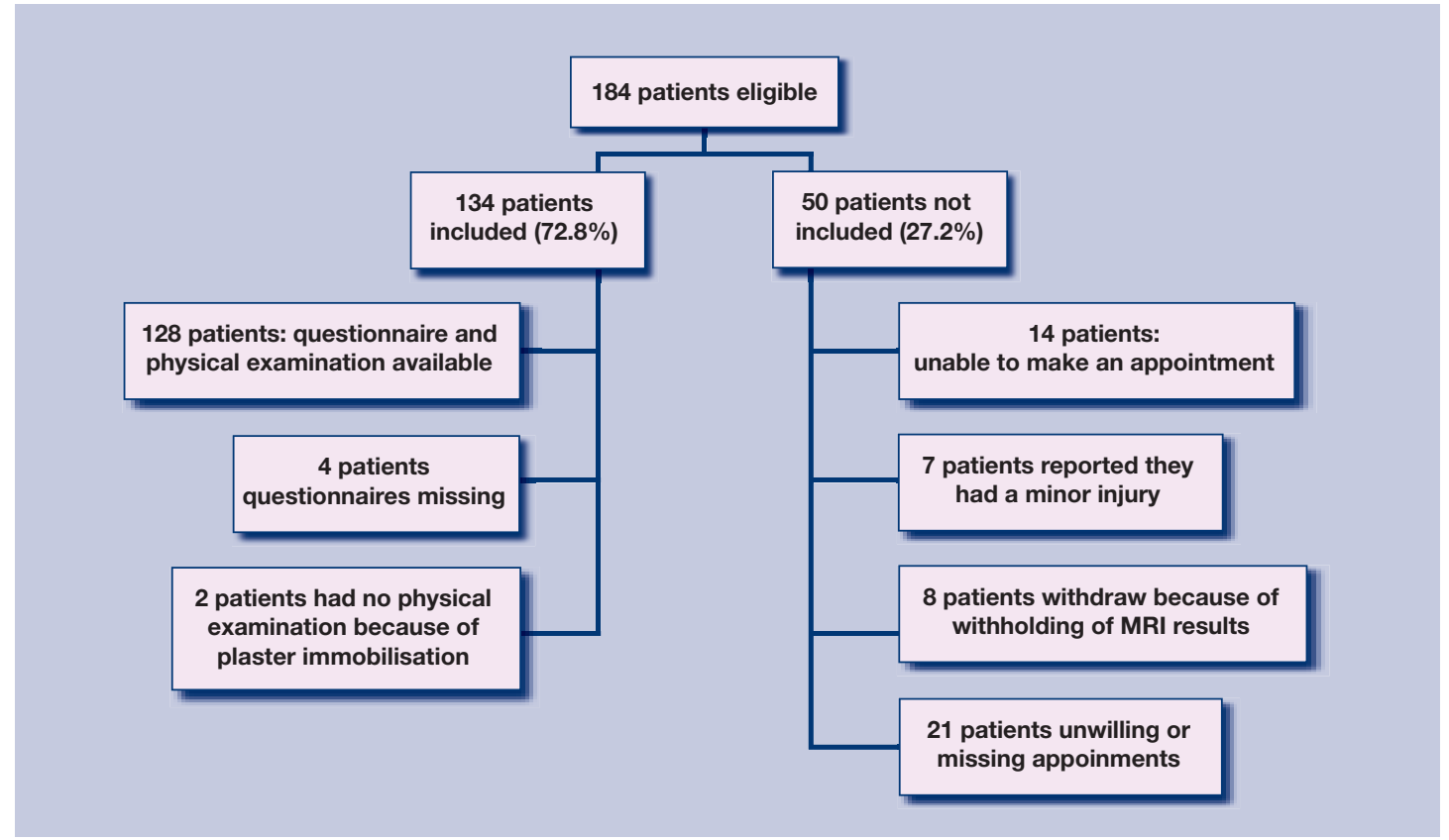

$=0.69[95 \%$ confidence interval $\{\mathrm{Cl}\}=0.24$ to 1.28$]$ ), age (mean difference $[\mathrm{MD}] 0.2, P=0.92$ ), pain severity (MD 0.5, $P=0.22$ ), or Lysholm knee score (MD 3, $P=$ $0.40)$. No patient had to be excluded because of the exclusion criteria for the MRI.

\section{Table 1. Baseline characteristics of the participants and} non-participants.

\begin{tabular}{lcc} 
Characteristic & $\begin{array}{c}\text { Participants } \\
(n=134)\end{array}$ & $\begin{array}{c}\text { Non-participants } \\
(n=50)\end{array}$ \\
\hline Age in years, mean (SD) & $40.2(12.2)$ & $40.4(11.3)$ \\
\hline Males, $n$ (\%) & $74(55)$ & $32(67)$ \\
\hline Females, $n$ (\%) & $60(45)$ & $18(33)$ \\
\hline BMI, mean (SD) & $26.4(4.3)$ & $28.1(4.8)$ \\
\hline SF-36 general health, mean (SD) & $76.1(18.0)$ & $79.9(15.6)$ \\
\hline CPV, mean (SD) & $34.0(6.8)$ & $34.1(7.5)$ \\
\hline Tampa score, mean (SD) & $7.2(7.7)$ & $7.8(9.4)$ \\
\hline Symptom side right, $n$ (\%) & $70(52)$ & $16(34)$ \\
\hline Pain severity (0-10), mean (SD) & $4.7(2.4)$ & $4.2(2.5)$ \\
\hline Lysholm knee function score (0-100), mean (SD) & $62(22)$ & $67(23)$ \\
\hline Employed, $n$ (\%) & $113(84)$ & $39(73)$ \\
\hline Sports participation, $n$ (\%) & $97(72)$ & $29(58)$ \\
\hline Cause of trauma & & \\
Work related, $n$ (\%) & $20(15)$ & $9(18)$ \\
Onset during sports activity, $n(\%)$ & $61(46)$ & $17(34)$ \\
\hline No lesion on MR imaging, $n$ (\%) & $52(39)$ & na \\
\hline Any lesion on MR imaging, $n(\%)$ & $82(61)$ & na \\
Isolated meniscal tear & na \\
Isolated cruciate ligament lesion ${ }^{b}$ & $18(13)$ & na \\
Isolated collateral ligament lesion & \\
Combination of meniscal tears and/or ligament lesion & $18(13)$ & na \\
\hline
\end{tabular}

${ }^{a}$ Horizontal, longitudinal, radial or complex meniscal tear. ${ }^{\mathrm{b}}$ Partial or complete anterior or posterior cruciate ligament lesion. 'Partial or complete medial or lateral collateral ligament lesion. $C P V=$ coping with pain. na = not available because of non-participation in the MRI study.
Baseline questionnaires were available for 130 patients $(97 \%)$. Some baseline characteristics from the remaining four patients were obtained from the physical examination or from the MRI procedure. The mean age of the participants was 40 years (range 18-64 years), and a small majority was male (55\%). Participation in sports was reported by 97 (72\%) of the 134 participating patients. Sixty-one (46\%) patients reported that the onset of the knee injury was during sports activity.

\section{MRI results}

In 52 patients (39\%), no meniscal tears or ligament lesions were seen on the MRI; eighty-two patients $(61 \%)$ showed either an isolated meniscal tear (18 patients, $13 \%$ ), an isolated cruciate (10 patients, $8 \%$ ) or collateral ligament lesion (18 patients, $13 \%$ ), or a combination of these (36 patients, $27 \%$ ).

\section{Follow-up}

At 3, 6, and 12 months' follow-up, 104 (78\%), 92 (69\%), and 112 (84\%) patients, respectively, returned the questionnaire. Another 10 patients reported their perceived recovery by telephone; thus perceived recovery was obtained from 122 patients (91\%), while 12 patients (9\%) were lost to follow-up; seven of them showed no lesion on the baseline MRI.

\section{Perceived recovery}

One hundred and twenty-two patients (91\%) reported on their perceived recovery (Table 2); 34 (28\%) reported full recovery and 67 (55\%) reported major improvement. Overall, 101 patients (83\%) reported a clinically relevant recovery, 18 patients (15\%) reported minor improvement or approximately 
Table 2. Perceived recovery in 122 patients at 12 months' follow-up.

\begin{tabular}{lccccc} 
Perceived recovery & $\begin{array}{c}\text { Full } \\
\text { recovery }\end{array}$ & $\begin{array}{c}\text { Major } \\
\text { improvement }\end{array}$ & $\begin{array}{c}\text { Minor } \\
\text { improvement }\end{array}$ & $\begin{array}{c}\text { Approximately } \\
\text { equal }\end{array}$ & $\begin{array}{c}\text { Minor } \\
\text { deterioration }\end{array}$ \\
\hline Total group $(n=122), n(\%)$ & $34(28)$ & $67(55)$ & $14(12)$ & $4(3)$ & $3(2)$ \\
\hline No lesion group $(n=45), n(\%)$ & $15(33)$ & $22(49)$ & $5(12)$ & $2(4)$ & $1(2)$ \\
\hline Any lesion group $(n=77), n(\%)$ & $19(25)$ & $45(59)$ & $9(12)$ & $2(2)$ & $2(2)$ \\
\hline Isolated meniscal tear $(n=17), n(\%)$ & $3(18)$ & $13(76)$ & $1(6)$ & 0 & 0 \\
\hline Isolated cruciate lesion $(n=10), n(\%)$ & $4(40)$ & $5(50)$ & $1(10)$ & 0 & 0 \\
\hline Isolated collateral lesion $(n=16), n(\%)$ & $3(19)$ & $11(69)$ & $2(12)$ & 0 & 0 \\
\hline Combination tear/lesion $(n=34), n(\%)$ & $9(27)$ & $16(46)$ & $5(15)$ & $2(6)$ & $2(6)$ \\
\hline
\end{tabular}

${ }^{a} 12$ patients were lost to follow-up (seven in no lesion group and five in lesion group).

equal status, and three patients $(2 \%)$ reported minor deterioration. One of these three latter patients underwent an anterior cruciate ligament reconstruction operation 10 months after initial trauma. No patient reported major deterioration or feeling worse than ever. In the 34 patients who reported full recovery, the median time to recovery was 5 months (range 2-12 months). Of the 15 patients that were operated on during the 12 months' follow-up, 10 (67\%) reported clinically relevant recovery.

\section{Severity of pain}

At baseline the mean pain severity score for the total study population was $4.8(\mathrm{SD}=2.4)$ (Table 3$)$. The mean pain score decreased to $2.5(\mathrm{SD}=2.3)$ at 3 months' follow-up, to $2.2(\mathrm{SD}=2.3$ ) at 6 months' follow-up, and to $1.8(\mathrm{SD}=2.3)$ at 12 months' follow- up. The subgroup with isolated cruciate ligament lesions had the lowest pain score both at baseline and over the entire study period (Figure 2). The subgroup with isolated meniscal tears had the highest mean pain score at baseline and during follow-up. The subgroup without lesion showed intermediate mean pain scores.

\section{Lysholm and Tegner knee score}

At baseline, the mean Lysholm score was $62(\mathrm{SD}=22)$ for the total study population (Table 3). The mean Lysholm score increased to $78(S D=19)$ at 3 months' follow-up, to $80(\mathrm{SD}=18)$ at 6 months' follow-up, and to $85(\mathrm{SD}=17)$ at 12 months' follow-up. At 12 months' follow-up, the subgroup with isolated cruciate ligament lesions reported the highest mean Lysholm knee score (Figure 3). At baseline the mean Tegner knee score was $4.5(S D=1.9)$. The mean Tegner score

\begin{tabular}{|c|c|c|c|c|}
\hline Variable & $\begin{array}{c}\text { Baseline, } \\
n=130\end{array}$ & $\begin{array}{c}0-3 \text { months }^{\mathrm{a}} \\
\quad n=104\end{array}$ & $\begin{array}{c}3-6 \text { months }^{a} \\
n=92\end{array}$ & $\begin{array}{c}6-12 \text { months }^{\mathrm{b}} \\
n=112\end{array}$ \\
\hline \multicolumn{5}{|c|}{ Pain score (NRS 0-10), mean \pm SD } \\
\hline Total group & $4.8 \pm 2.4$ & $2.5 \pm 2.3$ & $2.2 \pm 2.3$ & $1.8 \pm 2.3$ \\
\hline No lesion group & $4.9 \pm 2.3$ & $2.7 \pm 2.4$ & $2.2 \pm 2.4$ & $1.6 \pm 2.2$ \\
\hline Any lesion group & $4.7 \pm 2.5$ & $2.3 \pm 2.2$ & $2.2 \pm 2.2$ & $2.0 \pm 2.4$ \\
\hline \multicolumn{5}{|c|}{ Lysholm knee score $(0-100)$, mean $\pm S D$} \\
\hline Total group & $62 \pm 22$ & $78 \pm 19$ & $80 \pm 18$ & $85 \pm 17$ \\
\hline No lesion group & $64 \pm 23$ & $80 \pm 17$ & $81 \pm 18$ & $86 \pm 16$ \\
\hline Any lesion group & $60 \pm 22$ & $76 \pm 20$ & $80 \pm 18$ & $84 \pm 17$ \\
\hline \multicolumn{5}{|c|}{ Tegner function score $(0-10)$, mean \pm SD } \\
\hline Total group & $4.5 \pm 1.9$ & na & na & $4.1 \pm 1.8$ \\
\hline No lesion group & $4.5 \pm 1.8$ & na & na & $4.4 \pm 2.1$ \\
\hline Any lesion group & $4.4 \pm 2.0$ & na & na & $3.9 \pm 1.6$ \\
\hline \multicolumn{5}{|l|}{ Sick leave, $n(\%)$} \\
\hline $1-5$ days & $31(25)$ & $20(19)$ & $6(7)$ & $3(3)$ \\
\hline $6-10$ days & $4(3)$ & $9(9)$ & $3(3)$ & 0 \\
\hline$>10$ days & $7(5)$ & $16(15)$ & $3(3)$ & $1(1)$ \\
\hline Hindrance at work, $n$ (\%) & $76(59)$ & $30(29)$ & $20(12)$ & $14(13)$ \\
\hline Adaptation at work, $n(\%)$ & $25(19)$ & $16(15)$ & $9(10)$ & $9(8)$ \\
\hline
\end{tabular}

${ }^{\mathrm{a}}$ Reported over a period of 3 months. ${ }^{\mathrm{b}}$ Reported over a period of 6 months. na $=$ not available. 


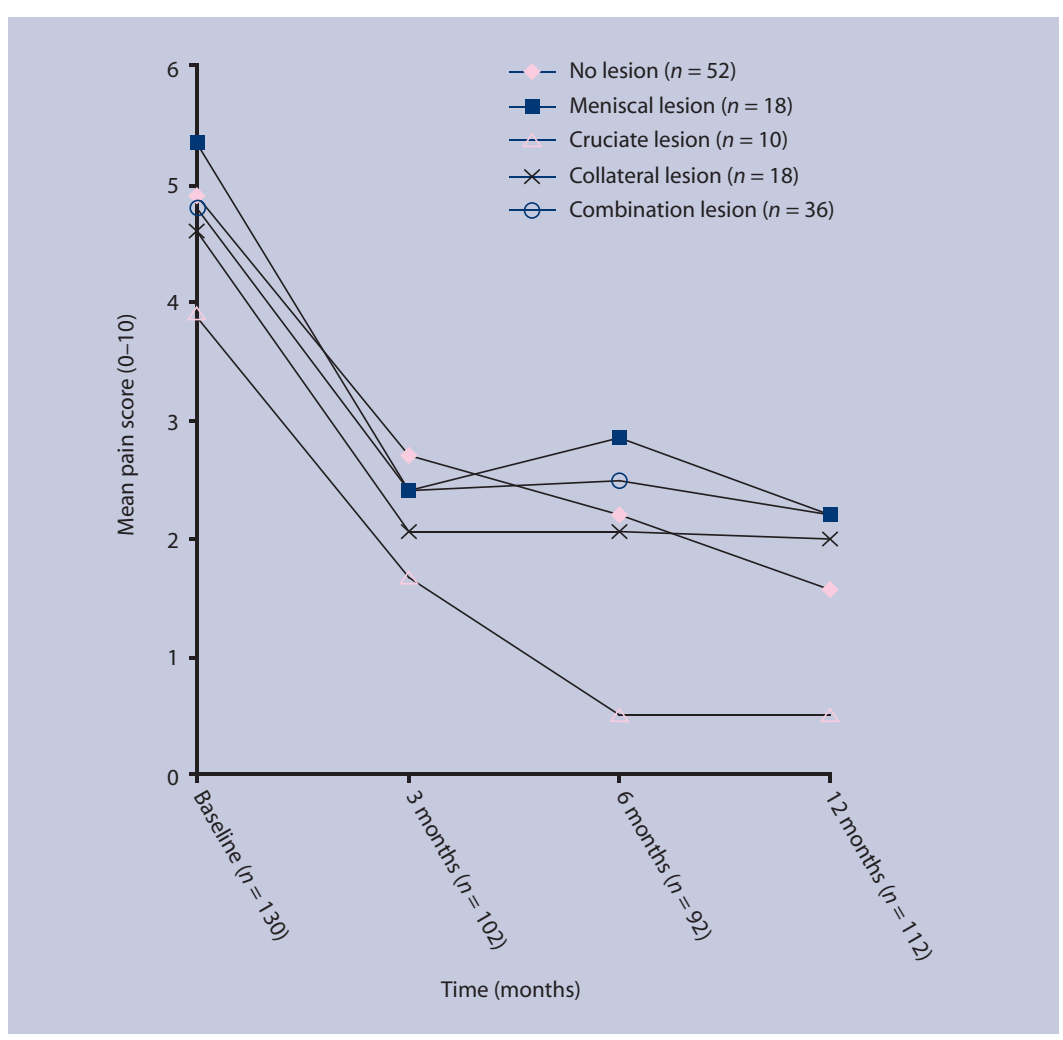

Figure 2. Pain score (NRS) for the various isolated and combination lesions.

Figure 3. Lysholm score for the various isolated and combination lesions. decreased to $4.1(\mathrm{SD}=1.8)$ at 12 months' follow-up.

\section{Management}

During the 12 months' follow-up, 54 patients (40\%) reconsulted the GP, with a total of 76 consultations (range 1 to 4 consultations) (Table 4). Of these 76

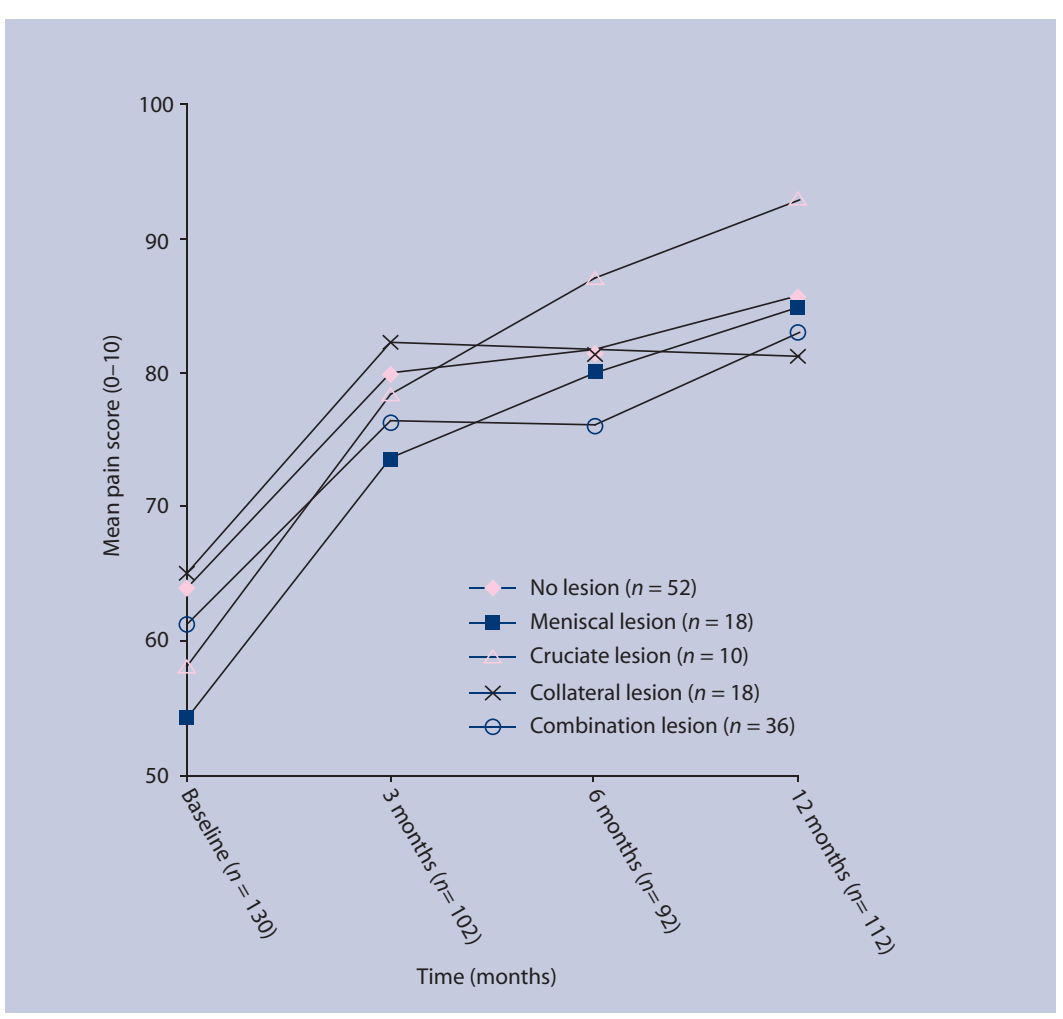

consultations, 27 (36\%) were made by patients without any lesion as seen on MRI. The majority of the reconsultations, namely $47(62 \%)$, took place during the first 3 months after the initial knee injury.

During the 12 months' follow-up, 47 patients $(27 \%)$ were referred to physical therapy, of which the majority of 37 patients (79\%) were referred at baseline (Table 4). Of these 37 patients, 14 (38\%) showed no lesion on MRI. During the 12 months' follow-up, 25 patients (19\%) were referred to secondary care. Again, the majority of these referrals, that is, 17 (68\%), took place at baseline; six of these patients had no lesion on the MRI. There was no clear pattern on referral to either physical therapy or secondary care in relation to determinants obtained by history taking or physical examination.

Over the 12-month study period, 18 arthroscopies were performed in 15 patients - either diagnostic or interventional. In seven cases a meniscal tear was involved as seen on the MRI. Collateral ligament lesions will not be treated operatively; however, in three patients arthroscopy was performed while six patients showed no meniscal tear or ligament lesion on MRI at all. In one of the patients with arthroscopy, an anterior cruciate ligament reconstruction was performed 10 months after the initial injury.

\section{DISCUSSION}

\section{Summary of main findings}

Information on perceived recovery was obtained from 122 patients of whom a majority of $83 \%$ reported clinically relevant recovery. The subgroups without lesion and with a lesion, as seen on MRI, showed no difference in clinically relevant perceived recovery. The subgroup without lesion had a higher percentage of loss to follow-up than the subgroup with any type of lesion.

The 50 non-participants in the present study showed no difference in clinically relevant perceived recovery compared with the participants $(81 \%$ versus $83 \%$, respectively). ${ }^{15}$

Almost $40 \%$ of the patients showed no meniscal or ligament damage on MRI but this subgroup still reported almost equal pain severity, Lysholm scores, and recovery rates compared to the patients with meniscal or ligament damage seen on MRI. This phenomenon might be explained by the fact that only meniscal and ligament damage were classified. Contusions, distortions and other abnormalities were not classified in this study; however, they can cause complaints and limitations in patients.

No clear relation emerges between the type of lesion and the severity of reported pain. The subgroup of patients with isolated meniscal tears showed the highest mean pain scores. This phenomenon may be explained by the degenerative 


\begin{tabular}{|c|c|c|c|c|c|}
\hline Management, $n(\%)$ & $\begin{array}{l}\text { Baseline } \\
n=130\end{array}$ & $\begin{array}{c}0-3 \text { months }^{\mathrm{a}} \\
n=104\end{array}$ & $\begin{array}{c}3-6 \text { months }^{\mathrm{a}} \\
n=92\end{array}$ & $\begin{array}{c}6-12 \text { months }^{b} \\
n=112\end{array}$ & $\begin{array}{c}\text { Total events/ } \\
\text { patients }^{\mathrm{c}}\end{array}$ \\
\hline \multicolumn{6}{|l|}{ Re-consulting the GP } \\
\hline Total group & - & 47 (45) & 17 (18) & $12(11)$ & $76 / 54$ \\
\hline No lesion & - & $14(26)$ & 5 (5) & $8(7)$ & $27 / 19$ \\
\hline Any lesion & - & $33(32)$ & $12(13)$ & $4(5)$ & $49 / 35$ \\
\hline \multicolumn{6}{|l|}{ Medication } \\
\hline Total group & $35(27)$ & $4(4)$ & $4(4)$ & $4(4)$ & $47 / 35$ \\
\hline No lesion & $14(11)$ & $2(2)$ & $1(1)$ & $1(1)$ & $18 / 14$ \\
\hline Any lesion & $21(16)$ & $2(2)$ & $3(3)$ & $3(3)$ & $29 / 21$ \\
\hline \multicolumn{6}{|c|}{ Referral to physical therapy } \\
\hline Total group & $37(22)$ & $11(11)$ & $4(4)$ & $6(6)$ & $58 / 54$ \\
\hline No lesion & $14(11)$ & $3(3)$ & $2(2)$ & $2(2)$ & $21 / 21$ \\
\hline Any lesion & $23(18)$ & $8(8)$ & $2(2)$ & $4(4)$ & $37 / 33$ \\
\hline \multicolumn{6}{|c|}{ Referral to secondary care } \\
\hline Total group & $17(13)$ & $5(5)$ & $2(2)$ & $4(4)$ & $28 / 26$ \\
\hline No lesion & $6(5)$ & $3(3)$ & 0 & $3(3)$ & $12 / 12$ \\
\hline Any lesion & $11(8)$ & $2(2)$ & $2(2)$ & $1(1)$ & $16 / 14$ \\
\hline \multicolumn{6}{|l|}{ Arthroscopy } \\
\hline Total group & - & $9(6)$ & $4(4)$ & $5(5)$ & $18 / 18$ \\
\hline No lesion & - & $2(2)$ & $1(1)$ & $3(3)$ & $6 / 6$ \\
\hline Any lesion & - & $7(7)$ & $3(3)$ & $2(2)$ & $12 / 12$ \\
\hline \multicolumn{6}{|l|}{ Surgery } \\
\hline Total group & - & 0 & 0 & 1 & $1 / 1$ \\
\hline No lesion & - & 0 & 0 & 0 & 0/0 \\
\hline Any lesion & - & 0 & 0 & 1 & $1 / 1$ \\
\hline
\end{tabular}

${ }^{a}$ Reported over a period of 3 months. ${ }^{\mathrm{b}}$ Reported over a period of 6 months. ${ }^{\circ}$ Total number of events over the number of patients involved during 1 year of follow-up.

aspects observed on MRI in both the injured knee and the contralateral knee. ${ }^{10}$ Also, this subgroup had the highest average age of 48 years, resulting in a higher proportion of degenerative aspects at the time of the injury. The subgroup with isolated cruciate ligament lesions showed the lowest pain score during the complete study period. This phenomenon might be explained by the fact that the average age in this subgroup (32 years) is more than 10 years lower than in other subgroups (range 42-48 years). The younger patients may have a more active lifestyle and therefore a better recovery. However, it might also indicate that isolated cruciate ligament lesions are indeed less painful.

The subgroup with a cruciate ligament lesion showed the highest Lysholm score at 6 and 12 months' follow-up. The Lysholm score is a combination score of functional limitations of which instability is only a single item. Only four of the 28 patients with an isolated or combined cruciate ligament lesion reported instability at 12 months' follow-up. The Tegner knee score showed that, on average, patients had some decrease in their level of activity during work and sport; however, this decrease was only marginal.

\section{Strengths and limitations of the study}

Patients with no lesions may have had fewer complaints and functional limitations and may be less motivated to participate during follow-up. The percentage of clinically relevant recovery in the present study may therefore be somewhat underestimated.

With regard to the management during the 12 months' follow-up, it is likely there was some underestimation due to recall bias because patients were asked retrospectively over a period of 3 or 6 months. It is also important to take into account the number of missing questionnaires during follow-up, leading to underestimation of the referral rate to either physical examination or secondary care, and the number of performed surgeries and arthroscopies.

Also, because knowledge of the diagnosis could have led to a different management and a different outcome, lesion diagnosis was not revealed to either the GP or the patient. As there were no standardised treatments following certain diagnoses, it is possible that specific management tailored to the diagnoses could have resulted in different outcomes.

\section{Comparison with existing literature}

The present study is, to the authors' knowledge, the first to report on the outcome of patients with a knee injury in a primary care setting. Of all included 
patients, $61 \%$ showed a meniscal tear, ligament lesion, or a combination on the MRI. Two studies reporting on knee injuries in emergency departments show similar percentages of abnormalities compared to the present results. ${ }^{17,18}$

Cardol et al reported that $25 \%$ of their patients were referred to secondary care, compared with only $13 \%$ in the present study. ${ }^{19}$ In the present study, GPs were aware of the fact that MRI was standard procedure and that injuries in need of immediate intervention (for example, fractures) would be noticed at the time of the MRI. Therefore the GP was less triggered to refer to secondary care. Because the spectrum of lesions involved in the present study and presented to the participating GPs is wide, it is reasonable to assume that this study population does represent the traumatic knee patient in general practice.

\section{Implications for future research and clinical practice}

The average time to full recovery was 5 months. The results of this outcome study seem to be in accordance with the Dutch general practice guideline for traumatic knee complaints which advocates a wait-and-see policy as a valid option for the majority of patients with traumatic knee disorders. ${ }^{8}$ The present results do not support the need for diagnostic evaluation by an orthopaedic surgeon during the first months after injury. Furthermore, it must be emphasised that this was an observational study with a follow-up for only 1 year. Marked differences between the lesion and no-lesion group (or within the lesion groups) might emerge with a longer follow-up (>12 months). One might expect an increased frequency of radiological osteoarthritis in those with meniscal or cruciate ligament damage..$^{20,21}$

Almost $45 \%$ of the study population consulted the GP again for their complaints, some patients more than three times in a period of 3 months. At baseline, referral to a physical therapist was almost equally distributed among patients with or without a lesion. This raises the question: on what grounds does a GP make a referral to the therapist? The same holds true for referral to secondary care; at baseline, almost the same percentage of patients with and without a lesion was referred to secondary care. To date, there is no strong evidence that physical therapy is effective in patients dealing with a meniscal tear or anterior cruciate ligament lesion. ${ }^{22,23}$ The same holds true for surgical intervention of meniscal tears and cruciate ligament lesions in secondary care..$^{24,25}$ The need for screening in secondary care in relation to the outcome or prognosis of patients with traumatic knee injuries also remains inconclusive. Studies concerning the strategy for GP referral to secondary care including the grounds and timing of referral are recommended. Studies with a longer follow-up duration (>12 months) are recommended, with particular focus on the relation between type of injury and the onset of osteoarthritis, as there is some evidence that a knee injury is an important risk factor for the development of osteoarthritis. ${ }^{26}$

\section{Funding body}

The research network Honeur was financially supported by the health insurance companies TRIAS, Zilveren Kruis Achmea, and OZ.

\section{Ethics committee}

The study protocol was approved by the medical ethics committee of Erasmus Medical Center Rotterdam.

\section{Competing interests}

The authors stated that there are none.

\section{Discuss this article}

Contribute and read comments about this article on the Discussion Forum: http://www.rcgp.org.uk/bjgp-discuss

\section{REFERENCES}

1. Linden MW van der WG, Bakker DH de, Schellevis FG. Tweede nationale studie naar ziekten en verrichtingen in de huisartspraktijk klachten en aandoeningen in de bevolking en in de huisartspraktijk. [Second national study on diseases and consultations in general practice]. Utrecht, Bilthoven: Nivel, Rijksinstituut voor volksgezondheid en milieu, 2004.

2. Calmbach WL, Hutchens M. Evaluation of patients presenting with knee pain: Part I. History, physical examination, radiographs, and laboratory tests. Am Fam Physician 2003; 68(5): 907-912.

3. Kostogiannis I, Ageberg E, Neuman P, et al. Activity level and subjective knee function 15 years after anterior cruciate ligament injury: a prospective, longitudinal study of nonreconstructed patients. Am J Sports Med 2007; 35(7): 1135-1143.

4. Swirtun LR, Renstrom P. Factors affecting outcome after anterior cruciate ligament injury: a prospective study with a six-year follow-up. Scand J Med Sci Sports 2008; 18(3):318-324.

5. Gillquist J, Messner K. Anterior cruciate ligament reconstruction and the long-term incidence of gonarthrosis. Sports Med 1999; 27(3): 143-156.

6. Daniel DM, Stone ML, Dobson BE, et al. Fate of the ACL-injured patient. A prospective outcome study. Am J Sports Med 1994; 22(5): 632-644.

7. Boks SS, Vroegindeweij D, Koes BW, et al. Follow-up of posttraumatic ligamentous and meniscal knee lesions detected at MR imaging: systematic review. Radiology 2006; 238(3): 863-871.

8. Plas CG van der DR, Hamel A. Guideline regarding traumatic knee problems [Dutch]. Huisarts Wet 1998; (41): 296-300.

9. Heintjes EM, Berger MY, Koes BW, Bierma-Zeinstra SM. Knee disorders in primary care: design and patient selection of the HONEUR knee cohort. BMC Musculoskelet Disord 2005; 6: 45

10. Boks SS, Vroegindeweij D, Koes BW, et al. Magnetic resonance imaging abnormalities in symptomatic and contralateral knees: prevalence and associations with traumatic history in general practice. Am J Sports Med 2006; 34(12): 1984-1991.

11. Paice JA, Cohen FL. Validity of a verbally administered numeric rating scale to measure cancer pain intensity. Cancer Nurs 1997; 20(2): 88-93.

12. Tegner Y, Lysholm J. Rating systems in the evaluation of knee ligament injuries. Clin Orthop Relat Res 1985; (198): 43-49.

13. Vincken PW, ter Braak BP, van Erkell AR, et al. Effectiveness of MR imaging in selection of patients for arthroscopy of the knee. Radiology 2002; 223(3): 739-746.

14. Oei EH, Nikken JJ, Verstijnen AC, et al. MR imaging of the menisci and cruciate ligaments: a systematic review. Radiology 2003; 226(3): 837-48.

15. Wagemakers HP, Heintjes EM, Boks SS, et al. Diagnostic value of history-taking and physical examination for assessing meniscal tears of the knee in general practice. Clin J Sport Med 2008; 18(1): 24-30.

16. Kastelein M WH, Luijsterburg PAJ, Verhaar JAN, et al. Diagnostic value 
of history taking and physical examination for assessing medial collateral ligament lesions of the knee in general practice. Am J Med 2008; 121(11): 982-88.

17. Oei EH, Nikken JJ, Ginai AZ, et al. Costs and effectiveness of a brief MRI examination of patients with acute knee injury. Eur Radiol 2009; 19(2): 409-418.

18. Nielsen AB, Yde J. Epidemiology of acute knee injuries: a prospective hospital investigation. J Trauma 1991; 31(12): 1644-1648.

19. Cardol M, Dijk L, van Jong JD, et al. Tweede Nationale Studie naar ziekten en verrichtingen in de huisartspraktijk Huisartsenzorg: wat doet de poortwachter? [Second National Survey of General Practice: General practice care: the work of the gatekeeper]. Utrecht/Bilthoven: NIVEL/RIVM, 2004

20. Lohmander LS, Englund PM, Dahl LL, Roos EM. The long-term consequence of anterior cruciate ligament and meniscus injuries: osteoarthritis. Am J Sports Med 2007; 35(10): 1756-1769.

21. Roos H, Adalberth T, Dahlberg L, Lohmander LS. Osteoarthritis of the knee after injury to the anterior cruciate ligament or meniscus: the influence of time and age. Osteoarthritis Cartilage 1995; 3(4): 261-267.

22. Trees AH, Howe TE, Grant M, Gray HG. Exercise for treating anterior cruciate ligament injuries in combination with collateral ligament and meniscal damage of the knee in adults. Cochrane Database Syst Rev 2007; (3): CD005961.

23. Thomson LC, Handoll HH, Cunningham A, Shaw PC

Physiotherapist-led programmes and interventions for rehabilitation of anterior cruciate ligament, medial collateral ligament and meniscal injuries of the knee in adults. Cochrane Database Syst Rev 2002; (2): CD001354.

24. Howell JR, Handoll HH. Surgical treatment for meniscal injuries of the knee in adults. Cochrane Database Syst Rev 2000; (2): CD001353.

25. Linko E, Harilainen A, Malmivaara A, Seitsalo S. Surgical versus conservative interventions for anterior cruciate ligament ruptures in adults. Cochrane Database Syst Rev 2005; (2): CD001356.

26. Cooper C, Snow S, McAlindon TE, et al. Risk factors for the incidence and progression of radiographic knee osteoarthritis. Arthritis Rheum 2000; 43(5): 995-1000. 